\title{
CIHR pledges to tackle primary health care
}

Published at www.cmaj.ca on Jan. 20

$\mathrm{T}$ he Canadian Institutes of Health Research (CIHR) will bolster support for research that tackles Canada's lacklustre primary health care performance, federal officials told a gathering of almost 500 primary health care practitioners and researchers in Toronto, Ontario, in January.

"Primary health care is the heart of all high-performing health systems," said Dr. Alain Beaudet, president of the granting council, which cosponsored the Primary Healthcare Summit along with the Canadian Medical Association and the Canadian Nurses Association.

"The attention we're focusing on this is long overdue," Beaudet added. "We're behind many industrial countries in translating research into action."

Colleen Flood, scientific director of CIHR's Institute of Health Services and Policy Research, warned that even as "provincial health ministries are staring down the barrel of financial constraint," a dose of strong medicine will be needed to tackle gaping deficiencies in primary care.

Roughly $36 \%$ of Canadians use hospital emergency departments for their primary health care, more than in any other industrialized country, said Flood, noting that Commonwealth Fund data places Canada at the bottom of the richcountry pile when it comes to wait times for providing emergency primary care (www.commonwealthfund.org /Content/Publications/In-the-Literature /2009/Nov/A-Survey-of-Primary-Care -Physicians.aspx).

Flood warned that Canada must overcome problems with primary care access, inadequate electronic records collection, "uncoordinated and sometimes duplicative" research and a "lack of knowledge application."

"We have some outstanding researchers but we clearly need more," she said, arguing that Canada must become an international leader in the

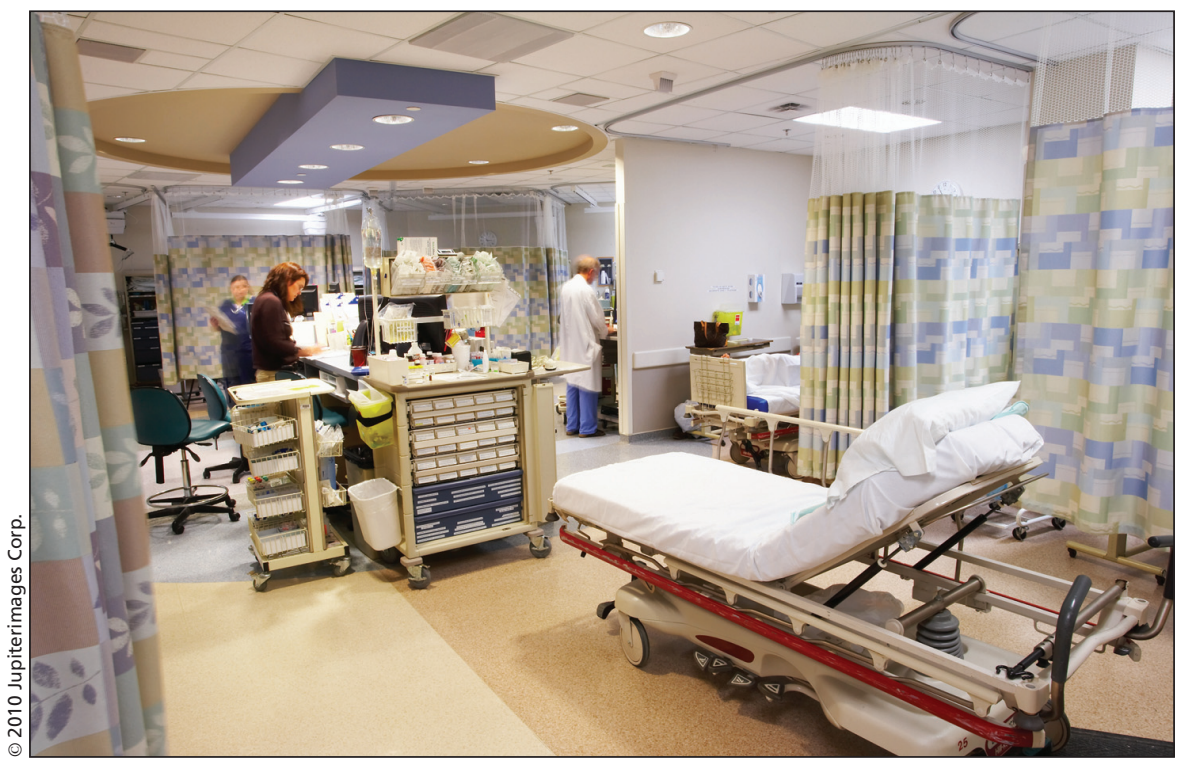

Canadian Institutes of Health Research officials estimate that $36 \%$ of Canadians use hospital emergency departments for their primary health care.

field by 2010. "Everybody's ducking for cover on primary health care research."

CIHR Senior Consultant Dale McMurchy noted Canada trails the primary care reform wave on many fronts: the involvement of nurses in chronic care management; online access to physicians, and the use of electronic medical records.

Meanwhile, medical and laboratory errors in Canada are 50\% higher than in France and trail only the United States among industrialized nations, McMurchy added.

All this at a time when patients are becoming "more active and more informed" about their physicians, even checking publication records, McMurchy said, while calling for greater accountability and transparency within the medical profession.

CIHR officials weren't alone in sounding the alarm. Michael Hindmarsh, a Toronto-based consultant, likened Canadian primary health care providers to pilots "trying to fly a plane and build a new one at the same time."

Hindmarsh pointed to an array of US Bureau of Primary Health Care studies that indicate outcomes are improved and costs are cut when primary health care is delivered by teams guided by a chronic care model that uses intensive data collection to support careful risk stratification and promotes patient self-management.

The model, which Hindmarsh helped develop and is now being applied in British Columbia and Saskatchewan, promotes the use of community-based primary health teams over hospital-based care.

But primary health care reform in Canada is happening "mostly in isolation from government," Hindmarsh added. "We need a national program for quality assurance and provider accountability. But there's no vision at the federal level, no push for a coordinated system and only very sporadic funding."

Hindmarsh also opined that professional associations are blocking primary health care innovations that might divert resources away from medical specialists and hospitals. "The professional associations are change averse. They are stuck in the past. But primary 
care is the direction we have to move. We have to shift resources away from hospitals and specialists."

Dr. Rob Wedel, a primary care physician who leads a team within Alberta's Chinook Primary Care Network, warned of a "tsunami of chronic disease" that threatens to overwhelm Canada's threadbare community health infrastructure.

Canada is ill-prepared to handle future volumes of aging patients with diseases requiring complex and carefully integrated management, he warned. While there are "pockets of innovation right across the Canadian health care system that are filling the evidentiary gaps," there's still a desperate need for more patient-centered research.

Beaudet later indicated in an interview that CIHR is prepared to devote a higher portion of its \$917-million budget to primary health research. He added that this is a common theme within many elements of CIHR's recently completed Five Year Strategic Roadmap (www.cihr-irsc.gc.ca/e/39977 .html). But the level and nature of CIHR investment has yet to be determined, Beaudet adds. "That's a decision we hope to be able to announce in the coming months." - Paul Christopher Webster, Toronto, Ont.

DOI:10.1503/cmaj.109-3160 